\title{
Research on the Application and Influence of AlIT on Accounting
}

\author{
Nan Shi ${ }^{1}$ \\ ${ }^{1}$ Tianjin Light Industry Vocational Technical College, Tianjin, China
}

Keywords: AIIT; Accounting; Application.

\begin{abstract}
The purpose of this paper is to give full attention to the development trend of information technology such as AIIT and network technology, and expand the accounting informationalized view. It also gives attention to the profound influence of AIIT on the cultivation of accounting professionals, change the existing accounting professional training system, build up an open, newfangled, smart accounting personnel training system on the basis of AIIT in response to the new opportunities and challenges of financial work in the age of informationalized big data.
\end{abstract}

\section{The Concept and Connotation of AIIT}

AIIT (Artificial Intelligence Information Technology) is a techical term of managing and handling all kinds of information by using technical methods in the field of artificial intelligence. It mainly applies computer science and communication technology to design, develop, install and implement information system and application software.

AIIT is not the kind of human intelligence, but it can think like a man and even do better. Recently, artificial intelligence has made great development and become a broad cross-cutting and cutting-edge science. When the computer emerged, human beings began to really have a tool to simulate the human mind.

\section{The Development and Application of AIIT on Accounting}

The Active Promotion and Application of Electronic Invoice and Electronic Accounting Archives. The revised Measures for the Administration of Accounting Archives has been implemented in January 1, 2016. The electronic invoice industry space is fully open. Since the electronic VAT invoices has been widely promoted over the nation, and revised Measures for the Administration of Accounting Archives has put electronic archives into the scope of accounting archives, The two catalysts of electronic invoice industry realized successively. The electronic invoice industry space is fully open. People can scan code directly or receive electronic invoices in PDF by email. Combining with online reimbursement system, employees don't need to stick tickets any more. Financial staff do not need to buy tickets and invoice manually by implementing electronic invoices in the enterprises. In the future, things like obtaining, reimbursing, recording and archiving of electronic accounting vouchers can realize electronic management. It compliances with the policy direction of "Internet Plus" Action promoted by the government. The biggest obstacle of electronic invoice promotion has been removed.

The Wide Technical Application of Paperless Reimbursement. Many enterprises are now using electronic apps to solve problems like reservations, conference trips, office supplies, and asset purchases. These intelligent applications have realized paperless reimbursement. Employees do not need to post tickets. Enterprises can settle accounts directly with these platforms. The audit work of financial personnel is delivered to the system. Compared with the traditional paper invoice, the electronic invoice has the advantages of paperless, low energy consumption, easy to save and easy to query. Especially for electronic suppliers, the cost of mailing is eliminated. For consumers, it has solved the defects of paper invoice in checking and preserving. For the tax departments, it is better to standardize management and data applications so that they can inquire, collect statistics and analyze the invoicing data of the taxpayers in time.

Integrate Development of Systems like New Financial Integration Software, Finance and Taxation. Through finance and tax integration software and various systems integration, electronic 
accounting will replace accounts to some extent. The system relies on mature and advanced technology to integrate finance, taxation, business management. The whole process is automatically handled by the system, humans are only assistants.

With the rapid development of artificial intelligence, Financial artificial intelligence can be embedded in financial planning and forecasting subsystem, financial decision-making subsystem, subsystems of financial budget, financial control and financial analysis subsystem. Through the integration of the system, the function of the financial artificial intelligence is fully developed. Financial projections are more accurate and financial decisions are more scientific. What' s more, financial budget will be more close to reality, financial control will be more accurate, financial analysis will be more thorough, and financial management will be more comprehensive. Everything will be managed more easily, fully and timely.

Financial Robots in Financial Audit. In March 2016, Deloitte announced to cooperate with artificial intelligence enterprises to introduce artificial intelligence into accounting, taxation and auditing. The action marks the artificial intelligence starts to influence accounting industry officially. The proportion of accounting and management in financial work has changed. The substitution of artificial intelligence for accountants is not a myth, but a topic for financial workers to face and ponder. The advantages of financial robots include:

Replace the high repetitive manual operations in the financial process;

Make judgments based on established business logic;

Identify the optimization points in the financial process;

The audit work will likely be implemented "full check" rather than "spot check";

Robots are more accurate than manual and work 24 hours a day;

Each step of the robot's mission can be monitored and recorded, which can be used as an audit evidence to meet compliance requirements;

The investment recycle period of robotic process automation technology is short, which can be low-cost integrated with the existing system.

\section{Changes and Challenges Led by AIIT in the Accounting Industry}

AIIT Provides An Entirely New Thought for the Financial Decisions of Enterprises. Data collection and analysis has always been a crucial part of the financial decision-making process. Under the background of "Big Data" era, data resources in the market are updating at an unprecedented speed. Vast amounts of data resources bring comprehensive source of information for the enterprise financial decision-making. At the same time, the relative degree of data resources and the reliability degree are the issues that must be considered in the decision-making process of the enterprise. The emergence and development of artificial intelligence provides an entirely new way of thinking about the financial decisions of the enterprise. The development of cognitive technology can help financial personnel integrate relevant data of the market environment and business operation. It can also accurately identify and collecte structured, semi-structured and unstructured data in the market environment and make it financial information which can be used directly by financial decision makers in the enterprises to make financial decisions scientifically and timely. This is critical for important decisions such as corporate investment and fund-raising.

AIIT Leads to Changes of Audit Mode. The audit work has always been an important guarantee to the order of the economic market. In addition to solid professional abilities, the auditors also need to have the patience to deal with the tedious data. The development of artificial intelligence has make it have the ability to turn human intelligence into productive capacity through science and technology. It is of great significance to the conduct of auditing work. At present, if most of the repeated mechanical and single data verification work can be taken by artificial intelligence, the auditor can put more time and energy into audit work of high quality. It can not only greatly reduce the workload of the auditors, but also improve auditors' efficiency and cultivate their keen market insight.

In addition, the development of artificial intelligence has focused on speeding up the whole financial data verification process by using information technology. Because artificial intelligence 
has the ability to deal with data rapidly and efficiently, the data resource processing in the audit process will no longer affect audit quality due to the heavy workload and high time cost. The audit process is simplified by using workflow automation technology, which means automation management of reporting, authorization, distribution and collection in the whole process. On one hand, auditors can identify different risks that exist in the reports by recognition technology. On the other hand, the smart technology can reduce financial risks to a large extent by comparing and parsing financial statements.

AIIT Offers Higher Requirements to Accounting Personnel. Artificial intelligence used in the field of accounting, will inevitably replace part of the accounting Personnel who do procedural, modular work. With artificial intelligence of relevant accounting and auditing work, the accounting personnel who engage in the basic accounting and auditing work and make no attempt to make progress are facing unprecedented challenges of the industry. On the contrary, those accountants and auditors who adjust fast and change positively will have more space to show their strength with the help of artificial intelligence.

The change in working patterns is a necessary process for traditional accounting personnel. Some accounting personnel can't keep up with times. They can neither use computer networking technology nor operate financial information software proficiently. They can' t even understand what is Shared Service Center and ERP. Their work stays in basic accounting and cannot move to higher financial management. As a result, their career life face a threat of stagnation. Some of the traditional accounting personnel can use the financial information technology proficiently, but since the work efficiency has been improved by financial electronization and informatization, enterprises no longer require a lot of basic accounting personnel, they also face the risk of unemployment.

\section{Accounting Personnel Should Actively Cope with the Development and the Changes of Times in Order Not to Be Eliminated.}

Change the Concept and Re-locate Accounting Talents as Advanced, Compound and Informationized. Accounting and auditing personnel should not satisfied with the existing state. They should have the ambition to become accounting and auditing talents as advanced, compound and informationized. They should continually export high-value accounting and audit services to the enterprise. They should keep refining targets, make plans and implement them strictly. They should also keep investing in themselves, improve their professional ability, and learn to summarize and think. It is also necessary for them to further study frequently. They should continuously enhance their abilities of communication, coordination and analysis. They should be familiar with industry dynamics. Moreover, they should actively expand knowledge and skills in the information field. All of these can make them transfer from the common accounting staff to the high-end financial management ones.

Focus on Big Data Analysis and Replace Empirical Analysis with Technical Analysis. At present, it is the period of the rapid development of the Internet technology revolution, and the data is the core resource. The age of big data is about to revolutionize society, and it will bring changes in thinking when analyzing data.

There are two ways of thinking reformation: One is that financial personnel are no longer used to random sampling, but learn to handle all the data. From account books to computers, from abaci to mouses, The information age brings great changes in aspects of both work and life for financial personnel. Financial work is increasingly oriented towards informatization, networking and elaboration. The other is that since financial personnel analyze and use all the data, the accuracy of the data is no longer the most important indicator. The financial and accounting personnel should pay more attention to correlation between various business. The advantages of AIIT are that it can calculate the cost more accurately, and help enterprises to effectively control the cost, and provide scientific, rational and accurate data support for enterprises' comprehensive budget.

The Transition from Financial Accounting to Management Accounting Has Become A Trend. The work of management accounting should not be restricted to accounting only. It is a 
comprehensive skill that goes beyond numbers. It makes the data controllable information. Management accounting should base on various flows and management links, and use data to speak, manage, improve and improve. The trend in the future is predictable. Staff in Regular business accounting, such as financing, auditing and taxation, will gradually decrease. This trend is gradual and inevitable.

Therefore, the accounting personnel should improve the level of knowledge and ability and make the transition to management accounting. They should improve their knowledge of finance and improve information literacy. They should use financial information to provide data support for managers' decisions. The age of big data requires accounting personnel to be more perceptive about information and data, as well as strategic analysis and judgment.

Recognize the Changes and Influence Brought by AIIT and Create New Ways of Management. The emergence and development of AIIT has gone through a long period of time. With the development of science and technology all around the world, AIIT is becoming more and more practical and efficient. Although the development of AIIT has made remarkable progress, it is still difficult to make the develop artificial "intelligence" to "wisdom".

The core of financial management is one's own judgment, analysis and decision. Only in this way can we realize the real value of it. The effectiveness of AIIT should be maximized to assist accounting personnel to create truly meaningful new ways of management.

In a word, the influence of the development of AIIT in finance is a business financial personnel and strategic financial personnel. It reminds us that believe it or not, the age is changing. What "Internet Plus" brings us is a double-edged sword. When it makes our life more convenient and improves work efficiency, a number of workers in all industries will be eliminated. Therefore, we must follow the footsteps of the age and try our best not be eliminated by it.

\section{References}

[1] Quanlei Bao, Study on the Development and Construction of Enterprise Intelligent Financial Decision Support System, Computer Knowledge and Technology. 2015-12-21

[2] Rong Cao, Yan Lin, Hongxin Bai, Study on the revolution Driven by Science and Technology of Training Accounting Professionals in Hebei Province, Journal of Baoding University. 2017-05-22

[3] Zixin Zhang, Xin Yang, Meng Xin, The Analysis of Chinese Business Theory on the Career Position of Accountants in the Application of Artificial Intelligence. 2016-11-18

[4] Yanxiang Sun, The Impacts of Artificial Intelligence on Accounting Work and Personnel, The Commercial Modernization. 2017-4-15

[5] Meng Li, Wenlian Wang, Research on Accounting Information Processing Intelligence [J]. Financial Communications (Academic). 2006-01 